\title{
Preface of the Second Edition
}

A book lives from and with its readers, with their criticism and ideas for innovations which significantly help to improve it. Five years after the first edition we have corrected the first one with respect to small inconsistencies and we added current results and literature to the respective chapters, in order to account for ongoing research. The most significant innovation of this second edition concerns the extension of Chapters 2 (Synthesis) and 4 (Function). These parts were a bit underrepresented in the first edition. Again, these chapters were written from a solid state chemistry point of view. We hope that the present edition is an attractive view on the broad family of intermetallics for Master and PhD students.

Also for the second edition, we got support from our co-workers and colleagues. We thank Gudrun Lübbering for literature search and administrative help, Prof. Dr. Hubert Huppertz for several technical photos and helpful discussions, Thomas Fickenscher for many of the photos of chapter 2, Dr. Florian Winter and Prof. Dr. Florian Kraus for critically reading the first edition, and PD Dr. Constantin Hoch for the electrocrystallization photo. We are indebted to the editorial and production staff of De Gruyter. Our particular thanks go to Kristin Berber-Nerlinger and Dr. Vivien Schubert for her continuous support during conception, writing and producing the present book.

Rainer Pöttgen, Dirk Johrendt

Münster, München, 18 December 2018

The book contains three different tokens, pointing to:

! safety-relevant experimental procedures

周园 list of references

recommended literature for further reading; i.e. relevant text books, review articles or important original articles 
